\title{
Acciones de mejora en una empresa distribuidora de semillas y fertilizantes del Valle del Yaqui, Sonora
}

\author{
Improvement actions in a seed and fertilizer distribution company in Valle del \\ Yaqui, Sonora
}

FORNÉS-RIVERA, René Daniel†*, CONANT-PABLOS, Marco Antonio, CANO-CARRASCO, Adolfo y SÁNCHEZ-CARREÓN, Alexia

Instituto Tecnológico de Sonora

ID $1^{\text {er }}$ Autor: René Daniel, Fornés-Rivera / ORC ID: 0000-0002-7438-0056, Researcher ID Thomson: G-3906-2018, CVU CONACYT ID: 280435

ID $1^{\text {er }}$ Coautor: Marco Antonio, Conant-Pablos / ORC ID: 0000-0002-3364-3702, Researcher ID Thomson: G-39112018, CVU CONACYT ID: 687331

ID $2^{\text {do }}$ Coautor: Adolfo, Cano-Carrasco / ORC ID: 0000-0002-3392-3667, Researcher ID Thomson: G-5035-2018, CVU CONACYT ID: 266064

ID $3^{\text {er }}$ Coautor: Alexia, Sánchez-Carreón / ORC ID: 0000-0001-8629-3040

DOI: $10.35429 / J E D .2019 .19 .6 .10 .17$

Recibido: 20 de abril de 2019; Aceptado: 20 de mayo de 2019

\begin{abstract}
Resumen
Esta investigación se desarrolla en una empresa elaboradora de fertilizantes inorgánicos y aborda la necesidad de adquirir la licencia sanitaria para mezclado y envasado de fertilizantes. Para ello, se requiere que se cumpla con los requisitos normativos que establece COFEPRIS y STPS en materia de manejo de residuos industriales y tóxicos con código (CRETIB) Corrosivo, Reactivo, Explosivo, Tóxico, Inflamable, InfecciosoBiológico. Actualmente se tiene un $17 \%$ de cumplimiento normativo representando un riesgo para la integridad de los empleados y la revisión de la licencia. El objetivo consistió en realizar acciones de mejora a través de los lineamientos establecidos por COFEPRIS para incrementar el porcentaje de cumplimiento de los mismos. El procedimiento fue: Describir el área bajo estudio, elaborar un listado de requisitos, medidas de seguridad, documento con la capacitación y difusión a los trabajadores, cédula de información técnica, inventario de las materias primas, equipo de protección personal y determinar el cumplimento de requisitos. Se entregaron ocho documentos los cuales fueron necesarios para dar cumplimiento a los requisitos establecidos cumpliendo con el objetivo e incrementando el porcentaje de un $17 \%$ a un $83 \%$ de cumplimiento.
\end{abstract}

\begin{abstract}
This research is carried out in a company that manufactures inorganic fertilizers and addresses the need to acquire a sanitary license for the mixing and packaging of fertilizers. For this, it is required to comply with the regulatory requirements established by COFEPRIS and STPS in the area of industrial and toxic waste management with code (CRETIB) Corrosive, Reactive, Explosive, Toxic, Flammable, Infectious-Biological. Currently there is a $17 \%$ regulatory compliance representing a risk to the integrity of employees and the revision of the license. The objective was to carry out improvement actions through the guidelines established by COFEPRIS to increase the percentage of compliance with them. The procedure was: Describe the area under study, prepare a list of requirements, security measures, document with training and dissemination to workers, technical information card, inventory of raw materials, personal protective equipment and determine the compliance of requirements. Eight documents were delivered which were necessary to comply with the requirements established in compliance with the objective and increasing the percentage from $17 \%$ to $83 \%$ compliance.
\end{abstract}

Risk, Security, Improvement

Citación: FORNÉS-RIVERA, René Daniel, CONANT-PABLOS, Marco Antonio, CANO-CARRASCO, Adolfo y SÁNCHEZ-CARREÓN, Alexia. Acciones de mejora en una empresa distribuidora de semillas y fertilizantes del Valle del Yaqui, Sonora. Revista de Desarrollo Económico. 2019, 6-19. 10-17

\footnotetext{
*Correspondencia al Autor (Correo Electrónico: rene.fornes@itson.edu.mx)

$\dagger$ Investigador contribuyendo como primer autor.
} 


\section{Introducción}

El hombre comenzó a cultivar las tierras desde hace miles de años y la fertilización se inició cuando los agricultores primitivos descubrieron que determinados suelos dejaban de producir rendimientos aceptables si se cultivaban continuamente, y que al añadir estiércol o residuos vegetales se restauraba la fertilidad (Ibáñez, 2017). La diversidad de cultivos tiene un peso importante a nivel mundial, puesto que impulsa a la seguridad alimentaria, y permite elevar el valor nutricional, combatir plagas, adaptarse a nuevos climas o incluso producir mayores rendimientos (Noticeres, 2016).

Para El economista (2019), IFAI (2016) y FAO (2016), entre 2006-2019, el consumo mundial de fertilizantes creció $1.8 \%$ y la producción a $2.3 \%$. Los principales productores son: China, Estados Unidos, Federación Rusa, India y Canadá, con $61.5 \%$ de la producción mundial, el consumo mundial fue de 209.6 millones de toneladas (mdt). Destaca China con $25.4 \%$ del total, seguido por Estados Unidos (13.0\%), India (12.3\%) y Brasil (7.2\%). En cuanto a su comercialización, 53\% se coloca en el mercado internacional. Rusia, China y Canadá, con $38.6 \%$ de las exportaciones, mientras que Estados Unidos, Brasil e India, son los principales importadores con $33 \%$. La Asociación Internacional de la Industria de los Fertilizantes (IFAI) estimó para el 2017-2018, una demanda de 187 mdt lo que representó un crecimiento de $1.3 \%$ con respecto al 20162017. Para el 2018-19 se prevé que la demanda mundial registre un menor crecimiento $(0.7 \%)$. Para el 2019-20 se pronostica un repunte de la demanda en $1.6 \%$ (191.4 mdt). La venta mundial fue estimada en $251 \mathrm{mdt}$ en el 2018, lo que representó un incremento de $1.2 \%$ con respecto al 2017. Las ventas mundiales fueron de 75\% en el 2017 (Bejarano, 2017).

Para el 2019, se pronostica una oferta incrementada en 1.2\%, al ubicarse en $254 \mathrm{mdt}$. Según el Banco Mundial (2019), habrá 9,700 millones de habitantes para el 2050; se requiere incrementar la producción de alimentos en un $70 \%$ para sustentar a más de nueve mil millones de personas en el mundo. La seguridad alimentaria es esencial para todas las personas. Sin embargo, y pese al excelente territorio con el que cuenta México para la producción agrícola, los suelos no están exentos a los daños que genera la poca rotación de cultivos.
Por su parte la ONU sostiene que se deben considerar medidas hacia el manejo, uso y disposición ecológicamente racional de plaguicidas y demás agroquímicos. Estas acciones están referidas en el Objetivo de Desarrollo Sostenible (ODS) 12: Producción y consumo responsables que en su meta 12.4 promueve, para 2020, la gestión ecológicamente racional de estos productos químicos (Bejarano, 2017)

$\mathrm{Al}$ conocer los problemas a la salud y el ambiente por estas sustancias, en México fue creada el 5 de julio de 2001 la Comisión Intersecretarial para el Control del Proceso y uso de Plaguicidas, Fertilizantes y Sustancias Tóxicas (CICOPLAFEST), ahora COFEPRIS (Comisión Federal para la Protección Contra Riesgos Sanitarios), su función es proteger a la población contra riesgos a la salud provocados por el uso y consumo y exposición a factores ambientales y laborales, la ocurrencia de emergencias sanitarias y la prestación de servicios de salud mediante la regulación, control y prevención de riesgos sanitarios (García y Durga, 2012).

Problemas como el uso inadecuado de los plaguicidas ha causado daños ambientales en todos los lugares donde se han aplicado que, en muchos casos, han sido irreversibles o difícilmente reversibles. En buena medida esto ha ocurrido por falta de conocimientos sobre los riesgos para el ambiente asociados con el uso de estas sustancias (SEMARNAT, 2015). Los plaguicidas se utilizan para proteger los cultivos expuestos al ataque de insectos, hongos, bacterias, maleza, virus o roedores, se define como "todo tipo de sustancia o compuestos químicos predestinados a acciones de prevención, destrucción o control de cualquier plaga". (Yáñez-QuijadaI y Camarena-GómezII, 2019).

Las empresas encargadas de importar, comercializar y distribuir fertilizantes deben de servir de filtro para realizar controles en cuanto a la venta de sustancias químicas a los distribuidores y consumidores finales, llevando un registro de las cantidades y los tipos de materiales comercializados y los lugares de destino final, también deben verificar los clientes, con el propósito de evitar que estos químicos terminen en manos de personas al margen de la ley y las usen de forma ilícita (Quintanilla, 2014). 
Debido a los agentes químicos que se utilizan en los fertilizantes, los trabajadores están expuestos a riesgos laborales que son generados por la falta de información y esto va en aumento por el incumplimiento de la normatividad, y errores que se puedan presentar en el lugar de trabajo (SENASICA, 2019).

Según la FAO, sin productos para la protección de cultivos, la producción mundial de alimentos caería hasta un $40 \%$ debido a los problemas biológicos. Los animales están igualmente protegidos contra los parásitos y las enfermedades. Para Hernández, Malfavón y Fernández (2012) y STPS (2014) seguridad es el conjunto de normas, obras y acciones así como los instrumentos técnicos y legislativos requeridos para proteger la vida humana, prevenir riesgos en entornos que aseguren su vida y salud.

Para Suarez y Sani (2012), la seguridad y salud en el empleo de fertilizantes ha sido una de las principales preocupaciones de las organizaciones internacionales. Algunos productos agroquímicos como los plaguicidas son peligrosos para la salud de los trabajadores y la población en general, así como también para el medio ambiente; así mismo todas las personas responsables de la producción, importación, almacenamiento y venta tienen que garantizar que se utilicen en condiciones de seguridad y de salud.

La empresa se dedica a la formulación y venta de fertilizantes; y distribución de marcas de agroquímicos, semillas de hortalizas, maíz, sorgo y granos. Sus clientes son: uniones agrícolas, empresas, financieras, entre otras. Teniendo como proveedores a: Syngenta, Dupont, Bayer, Químia, innovak, Monsanto. Semillas: Ceres, Sakata, Western seed.

Los productos y servicios se comercializan en 12 sucursales en el noroeste del país. La planta está conformado por oficinas, baños, almacén de agroquímicos, de gráneles, de costales, de producto envasado, área de líquidos, oficina de almacén y cocina. (Gerencia, 2017).

En la tabla 1 se aprecian los productos que comercializa.

\begin{tabular}{|c|c|c|c|}
\hline $\begin{array}{l}\text { Mezclas } \\
\text { físicas }\end{array}$ & $\begin{array}{l}\text { Fertilzantes } \\
\text { sólidos }\end{array}$ & $\begin{array}{c}\text { Fertilizantes } \\
\text { líquidos }\end{array}$ & $\begin{array}{c}\text { Fertilizantes } \\
\text { solubles }\end{array}$ \\
\hline $\begin{array}{l}\text { Semerfix } \\
\text { maiz }\end{array}$ & Urea & $\begin{array}{l}\text { Acido } \\
\text { fosforico }\end{array}$ & $\begin{array}{ll}\text { Nitrato } & \mathrm{de} \\
\text { potasio } & \end{array}$ \\
\hline $\begin{array}{l}\text { Semerfix } \\
\text { tomate }\end{array}$ & $\begin{array}{l}\text { Sulfato de } \\
\text { amonio Gr }\end{array}$ & UAN-32 & $\begin{array}{l}\text { Nitrato de } \\
\text { calcio }\end{array}$ \\
\hline $\begin{array}{l}\text { Semerfix } \\
\text { papa }\end{array}$ & $\begin{array}{l}\text { Sulfato de } \\
\text { amonio std }\end{array}$ & $28-0-0-7 \mathrm{~s}$ & $\begin{array}{ll}\text { Nitrato } & \text { de } \\
\text { magnesio } & \end{array}$ \\
\hline $\begin{array}{l}\text { Semerfix } \\
\text { garbanzo }\end{array}$ & $\begin{array}{l}\text { Cloruro de } \\
\text { potasio }\end{array}$ & 2-0-12-Ca & $\begin{array}{l}\text { Cloruro de } \\
\text { potasio std }\end{array}$ \\
\hline $\begin{array}{l}\text { Semerfix } \\
\text { frijol }\end{array}$ & $\begin{array}{l}\text { Sulfato de } \\
\text { potasio }\end{array}$ & $5-0-0-8 s$ & $\begin{array}{l}\text { Sulfato de } \\
\text { magnesio }\end{array}$ \\
\hline $\begin{array}{l}\text { Semerfix } \\
\text { chile }\end{array}$ & & 4-0-14 & $\begin{array}{l}\text { Sulfato de } \\
\text { potasio std }\end{array}$ \\
\hline $\begin{array}{l}\text { Semerfix } \\
\text { caña }\end{array}$ & & 4-0-12 & \\
\hline
\end{tabular}

Tabla 1 Productos que ofrece la empresa

Fuente: Gerencia (2017)

En entrevista con el gerente, recalcó que existe la necesidad de cumplir con distintos requisitos para la obtención de una licencia sanitaria en establecimientos que fabrican, formulan, mezclan o envasan plaguicidas $y$ nutrientes vegetales establecidos por COFEPRIS. Los lineamientos se pueden apreciar en la tabla 2.

Lineamientos a cumplir para la obtención de licencia sanitaria

1. Plano general del establecimiento donde se indiquen las diferentes áreas, así como el croquis de localización de estas.

2. Programa de capacitación y difusión de los trabajadores.

3. Hoja de datos de seguridad de las sustancias toxicas o peligrosas que se manejan en el establecimiento

4. Lista de las medidas de seguridad que se aplican en el establecimiento.

5. Lista del equipo para el control de contaminantes.

6. Lista del equipo contra incendios.

7. Lista de las construcciones especiales.

8. Cédula de información técnica de establecimiento:

Descripción del proceso industrial, con su diagrama de flujo. Características de maquinaria y equipo por línea de producción.

9. Inventario de materias primas: Describir las características de los residuos industriales.

10. Cantidades, promedios diario.

11. Periodicidad de las descargas y disposiciones.

12. Residuos industriales: Describir las características de los residuos industriales.

13. Cantidades, promedio diario.

FORNÉS-RIVERA, René Daniel, CONANT-PABLOS, Marco Antonio, CANO-CARRASCO, Adolfo y SÁNCHEZ-CARREÓN, Alexia. Acciones de mejora en una empresa distribuidora de semillas y fertilizantes del Valle del Yaqui, Sonora. Revista de Desarrollo Económico. 2019 


\begin{tabular}{|ll|}
\hline 14. & Periodicidad de las descargas y disposiciones. \\
\hline 15. & $\begin{array}{l}\text { Inventario del equipo de protección personal por } \\
\text { area y proceso }\end{array}$ \\
\hline 16. & $\begin{array}{l}\text { Inventario del equipo de protección para el } \\
\text { desarrollo de actividades especiales en las que se } \\
\text { manejen productos de alta toxicidad y } \\
\text { peligrosidad. }\end{array}$ \\
17. & $\begin{array}{l}\text { Producto: Código CRETIB (Sólidos, líquidos, } \\
\text { lodos otros, } \\
\text { Disposición final) }\end{array}$ \\
\hline
\end{tabular}

Tabla 2 Lineamientos para licencia

Fuente: COFEPRIS (2019)

Además de cumplir con estos lineamientos de COFEPRIS se deberán realizar 11 estudios a la organización y a sus trabajadores, ver Tabla 3.

\begin{tabular}{|ll|}
\hline \multicolumn{2}{|l|}{ Lista de estudios a realizar } \\
\hline 1. & Estudio de polvo \\
2. & Estudio de tierras físicas \\
\hline 3. & Estudio de ruido \\
\hline 4. & Autorización de uso de suelo. \\
\hline 5. & $\begin{array}{l}\text { Exámenes médicos de nuevo ingreso. (Todo } \\
\text { personal de planta y temporales) }\end{array}$ \\
\hline 6. & Examen de colinesteraza. \\
\hline 7. & Química sanguínea de elementos básicos. \\
\hline 8. & Examen general de orina \\
\hline 9. & Grupo sanguíneo y RH (Solo para primera vez) \\
\hline 10. & Estudio radiológico de columna vertebral. \\
\hline 11. & $\begin{array}{l}\text { Examen radiológico pulmonar para } \\
\text { identificar posibles consecuencias por exposición } \\
\text { a polvos (Anual). }\end{array}$ \\
\hline
\end{tabular}

Tabla 3 Lista de estudios

Fuente: Adaptado de COFEPRIS (2019)

En entrevista con el supervisor de seguridad e higiene, menciona que el porcentaje de cumplimiento es bajo con respecto a los requisitos mencionados en la tabla 2 y 3 para continuar con operaciones normales, y de igual forma conocer la situación actual, para iniciar el trámite de la licencia sanitaria de envasado expedida por COFEPRIS, por lo que de no lograrse esto, se corre el riesgo de perjudicar las ventas, ya que se prohíbe la entrada y salida de las mezclas de los fertilizantes, resaltando la importancia de contar con los requisitos para garantizar la eficiencia y seguridad del producto registrado, lo cual es requisito para su venta y uso.

Cabe resaltar que el establecimiento sólo cumple con un $17 \%$ de los requisitos. Por lo tanto, se planteó que era necesario determinar acciones de mejora para incrementar el porcentaje de cumplimiento de los lineamientos establecidos por COFEPRIS.

\section{Metodología a desarrollar}

El objeto de estudio fue la planta. Los materiales fueron: a) lineamientos de COFEPRIS, utilizados para identificar los requisitos establecidos para la obtención de la licencia sanitaria de envasado; b) Norma NOM002-STPS-2010, utilizada para elaborar la lista de equipo de protección contra incendios, c) Norma NOM-005-STPS-1998 utilizada para elaborar las listas de medidas de seguridad; y d) Norma NOM-017-STPS-2008 utilizada para elaborar inventario de equipo de protección personal de cada área. El procedimiento fué: 1) conocer el área bajo estudio; 2) determinar el cumplimiento de requisitos de COFEPRIS; 3) elaborar documento de las medidas de seguridad que aplican en la organización; 4) elaborar programa de capacitación y difusión de los trabajadores; 5) generar una cédula de información técnica; 6) realizar inventario de materias primas; 7) realizar inventario de equipo de protección personal; y 8) Evalaución de la mejora.

\section{Resultados}

Se presenta lo obtenido del procedimiento. Nota: Para efecto de los resultados del punto 3, 4, 5, 6, y 7 sólo se redactará una explicación o se agregará una lista de contenidos, ya que son tablas extensas.

\section{Conocer el área bajo estudio}

Se realizó una distribución de planta, ver Figura 1.

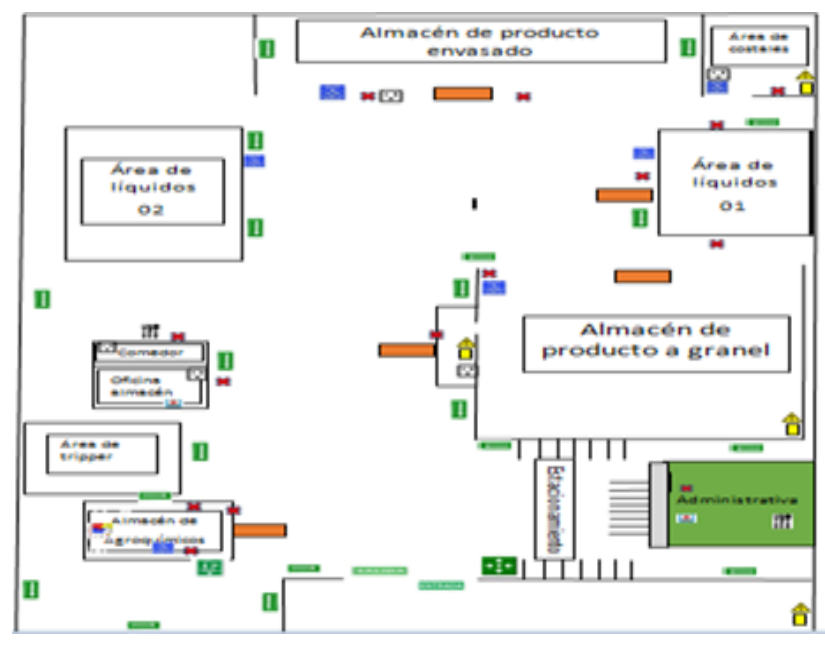

Figura 1 Distribución de planta 
La distribución muestra seis áreas: 1) almacén de agráneles; 2) área de mezclado y envasado; 3 ) área de agroquímicos; 4) almacén de especializados; 5) oficinas; y 6) área de líquidos.

\section{Determinación del cumplimiento de requisitos de COFEPRIS}

Se realizó una investigación en la página oficial (http://www.cofepris.gob.mx) para obtener los lineamientos y su estatus actual, ver Tabla 4.

\begin{tabular}{|c|c|}
\hline $\begin{array}{c}\text { Cumplimiento } \\
(\%)\end{array}$ & $\begin{array}{c}\text { Requisitos para licencia } \\
\text { sanitaria para establecimientos } \\
\text { que fabrican, formulan, mezclan } \\
\text { o envasan plaguicidas y } \\
\text { nutrientes vegetales }\end{array}$ \\
\hline $100 \%$ & $\begin{array}{l}\text { Plano general del establecimiento } \\
\text { donde se indiquen las diferentes } \\
\text { áreas, así como el croquis de } \\
\text { localización de éstas. }\end{array}$ \\
\hline $0 \%$ & $\begin{array}{ll}\text { Programa de capacitación } & y \\
\text { difusión a los trabajadores. } & \end{array}$ \\
\hline $100 \%$ & $\begin{array}{l}\text { Hoja de datos de seguridad delas } \\
\text { sustancias tóxicas o peli grosas } \\
\text { que se manejan en el } \\
\text { establecimiento. }\end{array}$ \\
\hline $0 \%$ & $\begin{array}{l}\text { Lista de las medidas de seguridad } \\
\text { que se aplican en el } \\
\text { establecimiento. }\end{array}$ \\
\hline $0 \%$ & $\begin{array}{l}\text { Lista del equipo para el control de } \\
\text { contaminantes. }\end{array}$ \\
\hline $0 \%$ & Lista del equipo contra incendios. \\
\hline N/A & $\begin{array}{l}\text { Lista de las construcciones } \\
\text { especiales }\end{array}$ \\
\hline $0 \%$ & $\begin{array}{l}\text { Cédula de información técnica de } \\
\text { establecimientos }\end{array}$ \\
\hline $0 \%$ & Inventario de materias primas. \\
\hline $0 \%$ & Residuos Industriales \\
\hline $0 \%$ & $\begin{array}{l}\text { Inventario del equipo } \mathrm{de} \\
\text { protección personal por área } \mathrm{y} \\
\text { proceso. }\end{array}$ \\
\hline $0 \%$ & $\begin{array}{l}\text { Inventario del equipo de } \\
\text { protección para el desarrollo de } \\
\text { actividades especiales en las que } \\
\text { se manejen productos de alta } \\
\text { toxicidad y peligrosidad }\end{array}$ \\
\hline $0 \%$ & Producto \\
\hline \multicolumn{2}{|c|}{ Total de cumplimiento $17 \%$} \\
\hline
\end{tabular}

Tabla 4 Porcentaje de cumplimiento de los lineamientos de COFEPRIS

La tabla muestra 13 lineamientos de los cuales aplican 12 y solo se cumple con dos de ellos, obteniendo un total de $17 \%$ de cumplimiento.

\section{Elaboración de documento de medidas de seguridad que aplican en la organización}

Se revisó la normatividad de la STPS y se generaron tres resultados: a) medidas de seguridad; b) lista de equipo de protección contra incendios; y c) lista del equipo para el control de contaminantes; se describe cada uno:

a. Se generaron lineamientos a seguir a1) almacenamiento; a2) traslado; a3) manejo; y a4) tratamiento de envases vacíos;

b. Se realizaron listas de equipos contra incendio por área, por equipo, cantidad, tipo, y capacidad y la lista de brigadas contra incendio. En la figura 1 se muestra la localización de los extintores, equipo contra incendios, punto de reunión, ruta de evacuación, entre otros;

c. La lista de equipo para el control de contaminantes es: dos extractores, dos ventiladores de techo y las propias ventanas. En términos generales en este punto se arroja como resultado los siguientes manuales: 1) Información de generalidades; 2) almacenamiento; 3) traslado; 4) manejo; 5) tratamiento de envases vacíos; 6) lista del equipo contra incendio; y 7) lista del equipo para control de contaminantes.

\section{Elaboración de programa de capacitación y difusión de los trabajadores}

El documento muestra el programa general, las capacitaciones realizadas durante un año y la cantidad de personas que los han tomado; como de organización, de primeros auxilios, de uso y manejo de agroquímicos, de residuos peligrosos, de extintores, de evacuación de inmuebles. La estructura del programa es: 1) objetivo; 2) etapas del programa; 3 ) estrategias para la capacitación; 4) instrumentación; 5) seguimiento del programa; y 6) programa general. 


\section{Generación de cédula de información técnica}

Se realizó una descripción genérica quedando: a) diagrama de flujo del proceso; y b) características de la maquinaria y equipo, resultando una cédula de información técnica, ver Figura 2.

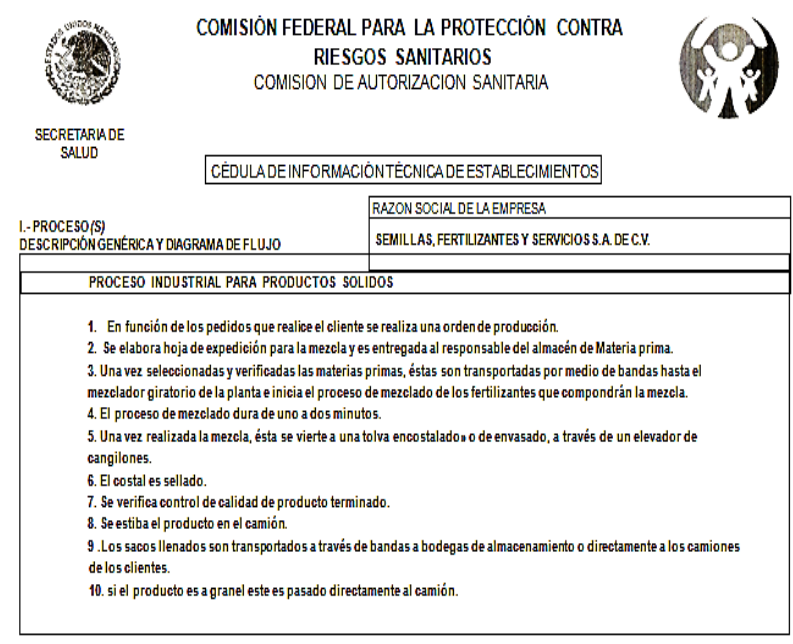

Figura 2 Cédula de información técnica

En esta cédula se muestra el proceso de producción de mezclado de fertilizante.

\section{Realización de inventario de materias primas}

Se identificó en almacenes las materias primas (se muestra sólo una parte en la tabla) ver tabla 5.

\begin{tabular}{|c|c|c|c|c|c|}
\hline $\begin{array}{l}\text { No. de } \\
\text { CAS }\end{array}$ & $\begin{array}{l}\text { Nombre } \\
\text { común }\end{array}$ & $\begin{array}{l}\text { Tipo de } \\
\text { envase }\end{array}$ & Capacidad & $\begin{array}{l}\text { Existencia } \\
\text { En kg }\end{array}$ & $\begin{array}{c}\text { Consumo } \\
\text { mensual } \\
\text { (toneladas) }\end{array}$ \\
\hline $\begin{array}{l}7447- \\
40-7\end{array}$ & $\begin{array}{ll}\text { Cloruro de } \\
\text { Potasio } \\
\text { Granular }\end{array}$ & Saco & $50 \mathrm{~kg}$ & 10914 & 9.58 \\
\hline & $\begin{array}{ll}\text { MAP } & \\
\text { granular } \\
\text { granel }\end{array}$ & \multirow{3}{*}{ A granel } & \multirow{3}{*}{--------- } & \multirow{3}{*}{1457.15} & \multirow{3}{*}{171.08} \\
\hline $\begin{array}{l}7722- \\
76-1\end{array}$ & $\begin{array}{l}\text { Dihidrogeno } \\
\text { ortofosfato } \\
\text { de amonio }\end{array}$ & & & & \\
\hline \multirow[t]{2}{*}{$\begin{array}{l}7783- \\
28-0\end{array}$} & $\begin{array}{l}\text { Hidrogenoor } \\
\text { tofosfato de } \\
\text { diamonio }\end{array}$ & & & & \\
\hline & $\begin{array}{l}\text { Prosimicros } \\
484\end{array}$ & \multirow{7}{*}{ Saco } & \multirow{7}{*}{$25 \mathrm{~kg}$} & \multirow{7}{*}{7350} & \multirow{7}{*}{1.7} \\
\hline $\begin{array}{l}7439- \\
89-6\end{array}$ & Hierro & & & & \\
\hline $\begin{array}{l}7440- \\
66-6\end{array}$ & Zinc & & & & \\
\hline $\begin{array}{l}7439- \\
96-5\end{array}$ & Manganeso & & & & \\
\hline $\begin{array}{l}7439- \\
89-6\end{array}$ & Boro & & & & \\
\hline $\begin{array}{l}7439- \\
95-4 \\
\end{array}$ & Magnesio & & & & \\
\hline $\begin{array}{l}14808- \\
60-7\end{array}$ & Silice & & & & \\
\hline
\end{tabular}

\begin{tabular}{|c|c|c|c|c|c|}
\hline $\begin{array}{l}\text { No. de } \\
\text { CAS }\end{array}$ & $\begin{array}{l}\text { Nombre } \\
\text { común }\end{array}$ & $\begin{array}{l}\text { Tipo de } \\
\text { envase }\end{array}$ & Capacidad & Existencia & $\begin{array}{c}\text { Consumo } \\
\text { mensual } \\
\text { (toneladas) }\end{array}$ \\
\hline & $\begin{array}{l}\text { Prosimicros } \\
\text { z-37 }\end{array}$ & \multirow{4}{*}{ Saco } & \multirow{4}{*}{$25 \mathrm{~kg}$} & \multirow{4}{*}{1835.73} & \multirow{4}{*}{1.13} \\
\hline $\begin{array}{l}7440- \\
66-6\end{array}$ & Zinc & & & & \\
\hline $\begin{array}{l}7439- \\
95-4\end{array}$ & Magnesio & & & & \\
\hline \multirow[t]{2}{*}{$\begin{array}{l}7439- \\
89-6\end{array}$} & Hierro & & & & \\
\hline & Qrop Boro & \multirow{10}{*}{ Saco } & \multirow{10}{*}{$50 \mathrm{~kg}$} & \multirow{10}{*}{3305} & \multirow{10}{*}{2.75} \\
\hline $\begin{array}{l}7440- \\
23-5\end{array}$ & Sodio & & & & \\
\hline $\begin{array}{l}7732- \\
18-5\end{array}$ & Agua & & & & \\
\hline $\begin{array}{l}7440- \\
38-2\end{array}$ & Arsénico & & & & \\
\hline $\begin{array}{l}7440- \\
70-2\end{array}$ & Calcio & & & & \\
\hline $\begin{array}{l}07 / 09 / 74 \\
40\end{array}$ & Potasio & & & & \\
\hline $\begin{array}{l}7439- \\
95-4\end{array}$ & Magnesio & & & & \\
\hline $\begin{array}{l}7439- \\
89-6\end{array}$ & Fierro & & & & \\
\hline $\begin{array}{l}7757- \\
82-6\end{array}$ & Sulfato & & & & \\
\hline $\begin{array}{l}7647- \\
14-5\end{array}$ & Cloruro & & & & \\
\hline
\end{tabular}

Tabla 5 Inventario de materia prima

La tabla 5 muestra el número de CAS (Chemical Abstracts Service), nombre común del producto, tipo de envase, capacidad, existencia en $\mathrm{Kg}$, y consumo promedio mensual en toneladas.

\section{Realización de inventario de equipo de protección personal}

Se contabilizo el equipo de protección personal que utilizan los trabajadores y productos de alta toxicidad y peligrosidad en cuatro áreas, las cuales son: 1) agroquímicos; 2) líquidos; 3) mezclado y envasado; y 4) especializados. En estas tablas (se mencionó antes que por extensión no se mostrarán las mismas) se puede observar que no se cuenta con equipos de protección, por lo cual se le hizo saber al encargado administrativo para la adquisición de estos para así poder dar cumplimiento a lo establecido por COFEPRIS y la STPS.

\section{Evaluación de la mejora}

Se determinó el porcentaje de cumplimiento alcanzado, después de implementar las acciones correspondientes teniendo como resultado un porcentaje, el cual se aprecia en la Tabla 6. 


\begin{tabular}{|l|l|}
\hline $\begin{array}{c}\text { Cumplimiento } \\
(\%)\end{array}$ & $\begin{array}{l}\text { Requisitos para licencia sanitaria } \\
\text { para establecimientos que } \\
\text { fabrican, formulan, mezclan o } \\
\text { envasan plaguicidas y nutrientes }\end{array}$ \\
\hline $100 \%$ & $\begin{array}{l}\text { Plano general del establecimiento } \\
\text { donde se indiquen las diferentes } \\
\text { áreas, así como el croquis de } \\
\text { localización de éstas. }\end{array}$ \\
\hline $100 \%$ & $\begin{array}{l}\text { Programa de capacitación y } \\
\text { difusión a los trabajadores. }\end{array}$ \\
\hline $100 \%$ & $\begin{array}{l}\text { Hoja de datos de seguridad delas } \\
\text { sustancias tóxicas o peli grosas } \\
\text { que se manejan en el } \\
\text { establecimiento. }\end{array}$ \\
\hline $100 \%$ & $\begin{array}{l}\text { Lista de las medidas de seguridad } \\
\text { que se aplican en el } \\
\text { establecimiento. }\end{array}$ \\
\hline $100 \%$ & $\begin{array}{l}\text { Lista del equipo para el control de } \\
\text { contaminantes. }\end{array}$ \\
\hline $100 \%$ & Lista del equipo contra incendios. \\
\hline N/A & $\begin{array}{l}\text { Lista de las construcciones } \\
\text { especiales }\end{array}$ \\
\hline $100 \%$ & $\begin{array}{l}\text { Cédula de información técnica de } \\
\text { establecimientos }\end{array}$ \\
\hline $100 \%$ & Inventario de materias primas. \\
\hline $0 \%$ & $\begin{array}{l}\text { Residuos Industriales } \\
\text { persontario del equipo de protección }\end{array}$ \\
\hline $100 \%$ & $\begin{array}{l}\text { Inventario area y proceso. equipo de protección } \\
\text { para el desarrollo de actividades } \\
\text { especiales en las que se manejen } \\
\text { productos de alta toxicidad y } \\
\text { peligrosidad }\end{array}$ \\
\hline $100 \%$ & Producto \\
\hline Total de cumplimiento 83\%
\end{tabular}

Tabla 6 Estatus actual alineado a COFEPRIS

\section{Conclusiones}

Se aprecia un $83 \%$, lo cual implica estar más cerca de la obtención de la licencia sanitaria y dar confianza y certeza a empleados y población en cuanto a su seguridad y potenciales impactos ambientales por malos manejos.

Se cumple con el objetivo planteado de la investigación al lograr incrementar el porcentaje de cumplimiento de un $17 \%$ a un $83 \%$ evidenciando que es muy importante atender el cumplimiento de normatividad al implementar las diversas acciones planteadas, evidenciando áreas de oportunidad como el abastecimiento oportuno de equipos de protección, inventarios de materia primas, y cedula técnica, especificando el proceso de producción de mezclado, lo que le permitirá a la empresa, en dado caso de que se genere alguna auditoria respaldarse con la documentación ya elaborada.

\section{Recomendaciones}

Se recomienda atender de forma inmediata el equipamiento adecuado para las diversas operaciones riesgosas y mantener vigente la normatividad de la STPS y COFEPRIS, lo cual dará certeza a empleados, clientes y sociedad en general, teniendo un impacto a nivel local, regional, estatal y nacional.

\section{Referencias}

Banco Mundial (2019). Agricultura y Alimento.Recupeado el 24 junio de 2019, de:https://www.bancomundial.org/es/topic/agri culture/overview

Bejarano, F. (2017). Los Plaguicidas Altamente Peligrosos en México. Recuperado el 26 de junio de 2019, de: https://www.uccs.mx/downloads/visit.php?id=fi le_59b5aa59d4322

COFEPRIS. (2019). ¿Que es la COFEPRIS?. Recuperado el 24 de junio 2019, de http://revistacofepris.salud.gob.mx/images/img/ 3artecofepris/arte.pdf

COFEPRIS. (2019). Licencia-Trámites. Recuperado el 01 de julio de: https://datos.gob.mx/busca/dataset/licenciassanitarias-para-fabricas-de-plaguicidas-ynutrientes-vegetales

El economista. (2019). Perspectivas del mercado mundial y nacional de los fertilizantes. Recuperado el 25 de junio de 2019, de: https://www.eleconomista.com.mx/opinion/Per spectivas-del-mercado-mundial-y-nacional-delos-fertilizantes-I-20190313-0102.html

FAO. (2016). El uso de fertilizantes sobrepasará los 200 millones de toneladas en 2018. Recuperado el 05 de Marzo de 2017, de http://www.fao.org/news/story/es/item/277654/i code/

García, C. y Durga, G. (2012). Problemática y riesgo ambiental por el uso de plaguicidas en Sinaloa. Ra ximhai. Recuperado el 20 Mayo de 2019 ,

de:http://www.redalyc.org/articulo.oa?id=4612 5177005 
Gerencia. (2017). Principal actividad de la empresa. (Montoya, N. y Sanchez, A. Entrevistadores).

Hernández, A., Malfavón, N., y Fernández, G. (2012). Seguridad e higiene industrial. México, D.F.: Limusa.

Ibáñez, D. (2017). Diseño de una planta de producción de fertilizantes NPK líquidos con una producción de $300 \mathrm{Tm} /$ día situada en el polígono industrial ''El Tossalet', de Bèlgida. (Tesis licenciatura, universidad politecnica de valencia).Recuperado en 26 de junio de 2019 , de:https://riunet.upv.es/bitstream/handle/10251/ 91209/IB\%C3\%81\%C3\%91EZ\%20\%20Dise\% C3\%B1o\%20de\%20una\%20planta\%20de\%20p roducci\% $\% 3 \% \mathrm{~B} 3 \mathrm{n} \% 20 \mathrm{de} \% 20$ fertilizantes $\% 20$ NPK\%20por\%20v\%C3\%ADa\%20de\%20mezcl a\%20\%C3\%A1cida\%2C\%20\%20con\%20\%20u ....pdf?sequence $=1$

IFAI. (2016). Mercado mundial de fertilzantes a corto plazo. Recuperado el 20 de Marzo de 2017 , de http://www.fertilizer.org/imis20/images/Library _Downloads/2015_ifa_paris_summary.pdf?We bsiteKey=411e9724-4bda-422f-abfc-

$8152 \mathrm{ed} 74 \mathrm{f} 306 \&=404 \% 3 \mathrm{bhttp} \% 3 \mathrm{a} \% 2 \mathrm{f} \% 2 \mathrm{fwww}$ .fertilizer.org\%3a80\%2fen\%2fimages $\% 2$ fLibra ry_Downloads\%2f2015_ifa_paris_summary.pd

SEMARNAT. (2015). Riesgos de los plaguicidas para el ambiente. Recuperado el 20 de febrero 2017, de:http://tramites.semarnat.gob.mx/Doctos/DG GIMAR/Guia/07-015AD/riesgos.pdf

Noticeres. (2016). Alimentación segura y diversa. Edición 45.

SENASICA. (Junio de 2019). Retos y Oportunidades para Fortalecer la Regulación Agrícola de Plaguicidas. Recuperado el 24 de junio de 2019, de https://www.paho.org/mex/index.php?option=c om_docman\&view=download\&slug=1357-11 retos-y-oportunidades-para-fortalecer-laregulacion-agricola-de-

plaguicidas $\&$ Itemid $=493$
Quintanilla, C. H. (Junio de 2014). Universidad militar nueva granada. Recuperado el 25 de Febrero de 2017, de:http://repository.unimilitar.edu.co:8080/bitst ream/10654/12777/1/principales $\% 20$ control $\% 2$ 0en $\% 201 \mathrm{a} \% 20$ comercializacion $\%$ c3\%93n\%20y $\% 20$ distribuci\%c3\%93n\%20de\%20fertilizantes \%20de\%20uso\%20agr\%C3\%8dcola\%20de\%20 venta $\% 20$ controlada $\% 20$ propuestos.pdf

STPS. (Noviembre de 2014). Reglamento federal de seguridad y salud en el trabajo. Recuperado el 01 de Marzo de 2017, de http://siaat.stps.gob.mx/Reglamento\%20Federal \%20de\%20SST.pdf

Suarez, A. y Sani, H. (2012). Plan de seguridad industrial en una planta de agroquímicos. (Tesis licenciatura, universidad de Guayaquil). Recuperado el 05 de Marzo de 2017, de: http://repositorio.ug.edu.ec/bitstream/redug/504 0/1/T204.pdf

Yáñez-QuijadaI A. I. y Camarena-GómezII, B. O. (2019). Salud ambiental en localidades agrícolas expuestas a plaguicidas en Sonora. Recuperado el 25 de Spetiembre de 2019, de: http://repositorio.upn.edu.pe/bitstream/handle/1 1537/21632/Zagaceta\%20Palp\%C3\%A1n\%2C $\% 20$ Eneyda\%20-

$\%$ 20Salvador\%20Alarc\%C3\%B3n\%2C\%20Cel ene.pdf? sequence $=1 \&$ is Allowed $=y$ 